\title{
Health effects of heating, ventilation and air conditioning on hospital patients: a scoping review
}

Benedikt Lenzer ${ }^{1,2^{*}}$ D, Manuel Rupprecht ${ }^{1}$, Christina Hoffmann ${ }^{1,2} \mathbb{D}$, Peter Hoffmann ${ }^{1,2}$ and Uta Liebers ${ }^{1}$

\begin{abstract}
Background: In the face of climate change, the protection of vulnerable patients from extreme climatic conditions is of growing interest to the healthcare sector and governments. Inpatients are especially susceptible to heat due to acute illness and/or chronic diseases. Their condition can be aggravated by adverse environmental factors. Installing air conditioning can be seen as an element of public health adaptation because it was shown to improve mortality rates of hospital patients experiencing hot temperatures. Still, the mediating factors and resulting health effects are largely unknown.

Method: The PRISMA-SCR guideline was followed for this scoping review. Available evidence on the health effects of Heating, Ventilation, Air Conditioning (HVAC) and fans was searched in Medline, Embase and the Cochrane Library. The focus of the search strategy was on inpatients of the hospital. Grey literature was screened on 14 relevant websites. English and German publications were eligible without restrictions on publication date. Results were charted according to the categories population, intervention, control and outcome together with a qualitative description.

Results: The review process yielded eleven publications of which seven were issued after 2003. Seven were clinical trials, three cross-sectional studies and one was a case report. The publications described the installation of HVAC on general wards and in intensive care units. Main topics were heat stress protection and support of thermoregulation, but also the rewarming of hypothermic patients. HVAC use resulted in a recovery effect shown by improved vital signs, reduced cardiac stress, accelerated recuperation and greater physical activity. This protective effect was demonstrated by a shorter hospital stay for patients with respiratory disease and a reduction of mortality for heat illness patients.

Conclusion: This scoping review summarises the fragmented evidence on health effects of HVAC and fan utilisation for inpatients. Installing HVAC has the potential to improve patients' outcomes and to make hospital treatment more efficient during heat waves. The application of HVAC could be a promising adaptation measure to mitigate the adverse effects of climate change on health and healthcare systems.
\end{abstract}

Keywords: HVAC, Electrical fan, Health facility environment, Hospital design, Climate change, Temperature, Heat, Cold, Patient comfort, Patient outcomes

\footnotetext{
* Correspondence: Benedikt.Lenzer@Charite.de

'Department of Outpatient Pneumology, Charité - Universitätsmedizin Berlin, corporate member of Freie Universität Berlin, Humboldt-Universität zu Berlin, and Berlin Institute of Health, Berlin, Germany

${ }^{2}$ Institute of Laboratory Medicine, Clinical Chemistry, and Pathobiochemistry,

Charité - Universitätsmedizin Berlin, corporate member of Freie Universität Berlin, Humboldt-Universität zu Berlin, and Berlin Institute of Health, Berlin, Germany
}

(c) The Author(s). 2020 Open Access This article is licensed under a Creative Commons Attribution 4.0 International License, which permits use, sharing, adaptation, distribution and reproduction in any medium or format, as long as you give appropriate credit to the original author(s) and the source, provide a link to the Creative Commons licence, and indicate if changes were made. The images or other third party material in this article are included in the article's Creative Commons licence, unless indicated otherwise in a credit line to the material. If material is not included in the article's Creative Commons licence and your intended use is not permitted by statutory regulation or exceeds the permitted use, you will need to obtain permission directly from the copyright holder. To view a copy of this licence, visit http://creativecommons.org/licenses/by/4.0/ The Creative Commons Public Domain Dedication waiver (http://creativecommons.org/publicdomain/zero/1.0/) applies to the data made available in this article, unless otherwise stated in a credit line to the data. 


\section{Background}

As global warming has become a reality, the mitigation of climate change and the creation of a climate change resilient healthcare system have become essential topics [1-4]. The World Meteorological Organization confirmed the continuing "long-term warming trend" based on five independently collected global datasets $[5,6]$. The increasing number of severe weather events, like heat waves, cold spells, extreme rainfalls or storms, will particularly negatively affect cities and hence stress the healthcare infrastructure typically found in urban areas $[1,2,7]$. One result is a rise in mortality and morbidity in heat-sensitive populations. Vulnerable groups include paediatric and adult patients with cardiovascular, renal or pulmonary disease but also patients with geriatric syndromes, heat-sensitive medication or bedridden individuals [1, 2, 8-13]. A meta-analysis showed that patients with chronic lung disease will have an increased mortality of at least $1.8 \%$ due to future heat waves [9]. A similar effect was also seen with hospital patients [14]. Additionally, reports on negative outcomes are emerging in disciplines like surgery or psychiatry which are often not in the centre of adaptation efforts $[15,16]$.

To this day, adaptation endeavours such as installing heat-health action plans remain behind the goals of the Paris Agreement of 2016 [2]. As infrastructure is the cornerstone of healthcare systems, explicit focus of hospitals on climate change-preparedness is necessary [2]. Installation of Heating, Ventilation, Air Conditioning (HVAC) in medical facilities is uncommon in Central and Northern Europe compared to Southern Europe or North America. This impairs the ability of these healthcare systems to cope with more frequent peaks of extreme weather conditions.

\section{What is known of the health effects of heating, ventilation and air conditioning?}

The current knowledge of HVAC related effects is based on studies on health issues in office workers [17] or on exercise-related heat illness $[18,19]$. Climatic influences on the physiology were tested with volunteers in climatic chambers [20, 21]. Moreover, many publications are concerned with the spread of infections $[17,22]$.

Equipping hospital rooms with some form of mechanical ventilation or air conditioning is one method to safeguard patients during heat or cold periods. The goal hereby is to ensure the quality of medical care and thermal comfort for patients and staff alike. An array of HVAC-systems is available, ranging from air conditioners or chillers to radiant cooling systems and fans. The protective effect of HVAC was demonstrated by a mortality reduction in private homes and hospitals [23-25]. However, since the examined studies were incoherent, a Cochrane review of the use of electrical fans did not yield conclusive results for or against the use in the general population [26].

Overall, studies on the effects of air conditioning on the health of inpatients are scarce. Knowledge of the mechanisms leading to effects on patient health when using HVAC is particularly insufficient. Hence, the first objective was to systematically screen the evidence on HVAC use and associated clinical effects or healthrelated outcomes in inpatients. The second objective was to identify relevant findings to generate new hypotheses for research on the efficacy of HVAC in climate change adaptation.

\section{Methods}

This research project was carried out according to the PRISMA Extension for Scoping Reviews (PRISMA-ScR) [27]. After a first non-systematic search, study registries were screened. One review project related to the topic could be identified (Prospero-ID: CRD42015018970), but progress status and email contact revealed no current activities. The protocol of our scoping review was registered on www.researchregistry.com (UIN: reviewregistry675).

\section{Eligibility criteria}

Literature on adult inpatients in English or German language was considered. The aim was to identify publications which reported health effects of all types of HVAC. Evidence on heating and cooling was included since many systems can technically be applied for both. Above all, through climate change different kinds of weather extremes will become more frequent. Articles that described direct body cooling methods such as fanning the body from a near distance were excluded. Literature on HVAC in the operating room or on infection rates was not within the scope of this review. Passive cooling interventions like window sunscreens were not included. Any date of publication was eligible to obtain a thorough overview of the published literature.

\section{Search process \\ Database search}

Medline, Embase and the Cochrane Library were searched. Within the search strategy of this review, the emphasis was put on clinically relevant parameters for internal medicine and pulmonology. Hence, search terms containing morbidity and mortality were not included in the search strategy. The full search strategy can be found in Additional file 1. The database search was carried out in April 2019.

\section{Grey Literature \& Other Sources}

14 websites of technical, medical and governmental organisations were screened (for web addresses see 
Additional file 2). The grey literature search was conducted in November 2019.

Title and abstract screenings were carried out by two reviewers with the web-based application Rayyan [28]. The full texts of potentially eligible publications were retrieved and screened against the inclusion criteria by two reviewers. Upon inclusion of full texts, the reference lists were hand-searched for further relevant literature. The authors of articles from the year 1990 onwards were contacted. Yet, no additional source of evidence and no further information on the type of HVAC appliances could be obtained. Relevant publications which were identified outside of the systematic search and also the primary sources of the systematic reviews were evaluated for eligibility. Duplicates were first identified with Endnote X9 (Clarivate Analytics, Boston/USA) and in a second step with Rayyan.

The data charting form (Additional file 3) was developed and tested with a sample of every different type of eligible publication identified. Charted data included the title, name of the authors, country of the first author, year and type of the study. The content was charted with the PICO scheme (Population, Intervention, Control, Outcome) where applicable. Additionally, publications were described qualitatively to capture all the relevant information regardless of study type. In this section, the field of application, addressed issues, problem statement and the findings of the publications were summarized. Data charting was performed by the first author and checked for completeness and accuracy by a second reviewer.

To delineate publications of HVAC use in medical treatment from publications only associated with HVAC use, the results are reported in two paragraphs. The first paragraph includes publications which report health effects of HVAC when used as a supportive element in medical treatment. Studies that reported the application of HVAC as part of a trial intervention were also included in this section. Publications were grouped in a short second paragraph if the HVAC system did not serve as intervention or no differentiation between air conditioning of the room and direct body cooling was made. All pieces of evidence are presented in two detailed tables. Conflicts regarding the inclusion of unusual HVAC designs or a fanning method were resolved by discussion within the reviewing team.

\section{Results}

\section{Database search}

Database search resulted in 13,625 titles. After duplicates were removed, 10,819 titles and abstracts were screened, leading to the evaluation of 23 full texts. The only eligible systematic review retrieved by database search was not included because hand-searching of the primary sources revealed no eligible publications. Based on the database search, nine full texts were considered for analysis in this scoping review (cf. Figure 1).

\section{Reference lists, other sources and grey literature}

Title and abstract screening of included publications and relevant other literature $[25,26,29]$ yielded 469 publications of which one eligible publication was included. One additional abstract from our department was incorporated in the scoping review [30].

After searching an extensive set of websites for grey literature, only six full text publications matched the scope of this review and were checked for eligibility. None of these publications was selected for the analysis.

\section{HVAC use in the medical treatment}

We identified seven publications reporting outcomes of HVAC use on patients which were published between 1959 and 2019 (cf. Table 1). This set consisted of five clinical trials [30-34], one cross-sectional study [35] and one case report [36]. Two publications were abstracts from conference proceedings [30,34]. No study reported concrete measures for matching or randomisation of study participants. The studies originated from the USA $(n=3)$, UK $(n=1)$, Germany $(n=2)$ and France $(n=1)$.

The reported HVAC systems ranged from conventional air conditioners to convection free air conditioning (radiant cooling) and fans. HVAC was implemented as a supportive element in the medical treatment with the goal of heat stress protection or as part of the rewarming strategy. HVAC was used on the general ward or the intensive care unit. The patient cohorts were comprised of patients with heat-stroke, hypothyroidism, pulmonary disease, diabetes mellitus, arthritis, goitre or patients who underwent intra-abdominal, pelvic, orthopaedic, peripheral vascular or prostatic surgery.

Regarding heat stress, the reported effects of cooling included improved blood pressure and respiratory rate and beneficial changes in cardiac function [30-32]. Particularly positive effects were observed in patients with chronic disease [31]. Notably, patients with congestive heart failure, coronary heart disease and asthma profited from the controlled room environment. Effects were described as a form of recovery effect from experiencing heat due to the use of air conditioning [30-32, 34]. The studies showed that equipping patient rooms with air conditioning led to earlier mobilisation [30, 31]. One study indicated a reduced length of hospital stay due to the use of radiant cooling [30]. Also, the protective effect of HVAC use in heat illness patients resulted in a reduction of mortality [35]. Only one study reported adverse effects [31]. Some patients perceived to get sick through air conditioning or described a negative impact on thermal comfort. However, the majority of patients and staff 


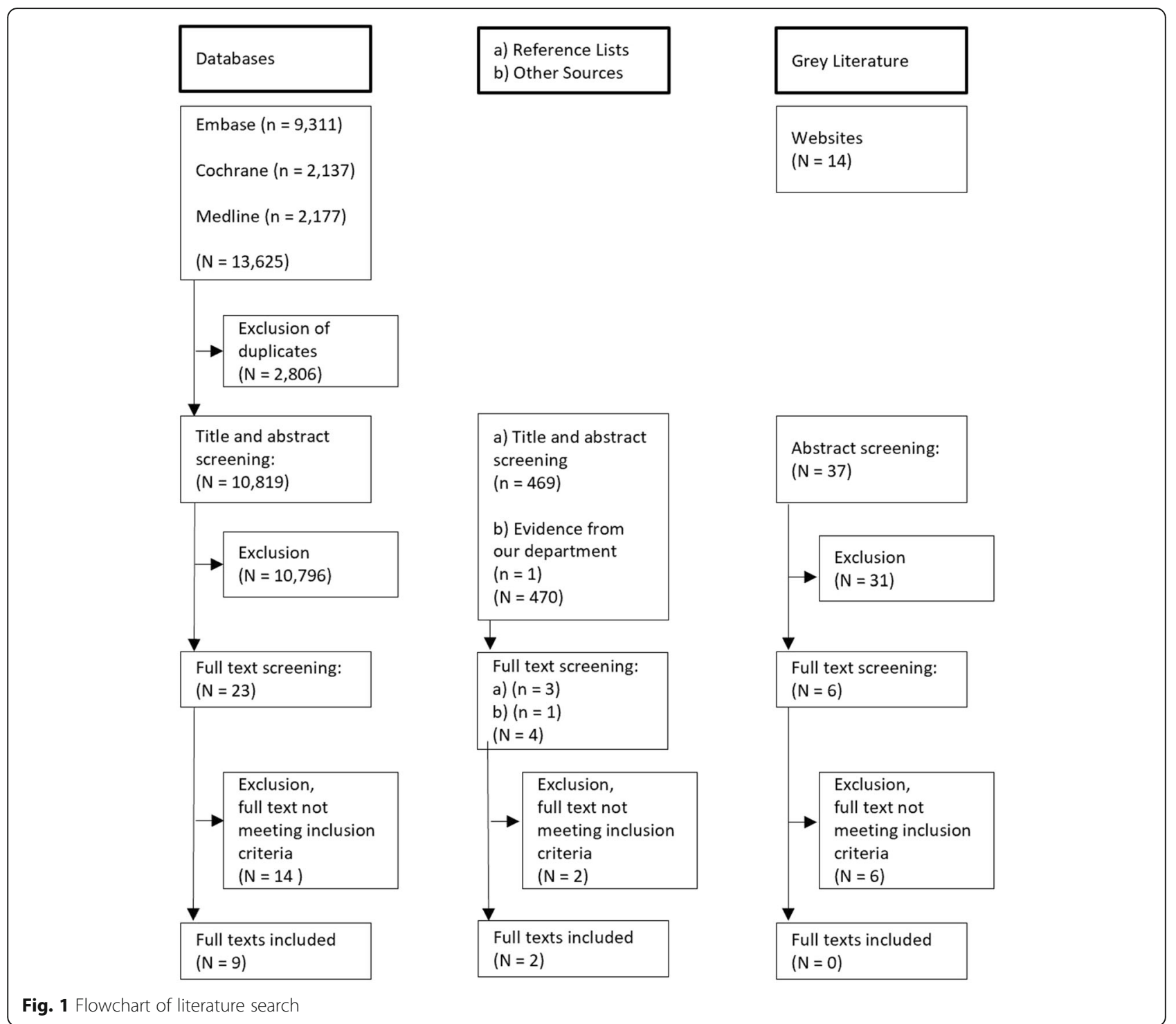

reported that air conditioning on the hospital ward was more beneficial to their overall well-being.

The use of HVAC in the recovery room showed no difference concerning the rewarming rate of postoperative patients [33]. Yet, the difference in room temperature between the two intervention groups was rather small $\left(0.5^{\circ} \mathrm{C}\right)$. HVAC utilisation was suggested as a supportive element in rewarming hypothyroid patients in one case report [36].

\section{Studies associated with HVAC use}

We identified two clinical trials $[37,38]$ and two crosssectional studies $[39,40]$ originating from the UK with relation to HVAC use, published between 1991 and 2018 (cf. Table 2). In these publications, either the application of the HVAC system could not be specified or no concrete health effects were reported. One publication was an abstract from a conference proceeding [40] and the remaining studies were journal articles.

The employment of HVAC was analysed in regard to the treatment of fever and fever combined with stroke or traumatic brain injury $[37,39,40]$. One study analysed the skin evaporation of patients with severe burns [39]. Fans, air conditioners, special air conditioning devices (clean air unit [41]) and other unspecified cooling methods were reported for the use in the intensive care unit.

\section{Discussion}

This scoping review resulted in the collation of 11 eligible publications from 1959 to 2019, whereof seven reported the use of HVAC as part of the medical treatment. The reported objectives were heat stress protection, body temperature management and the 


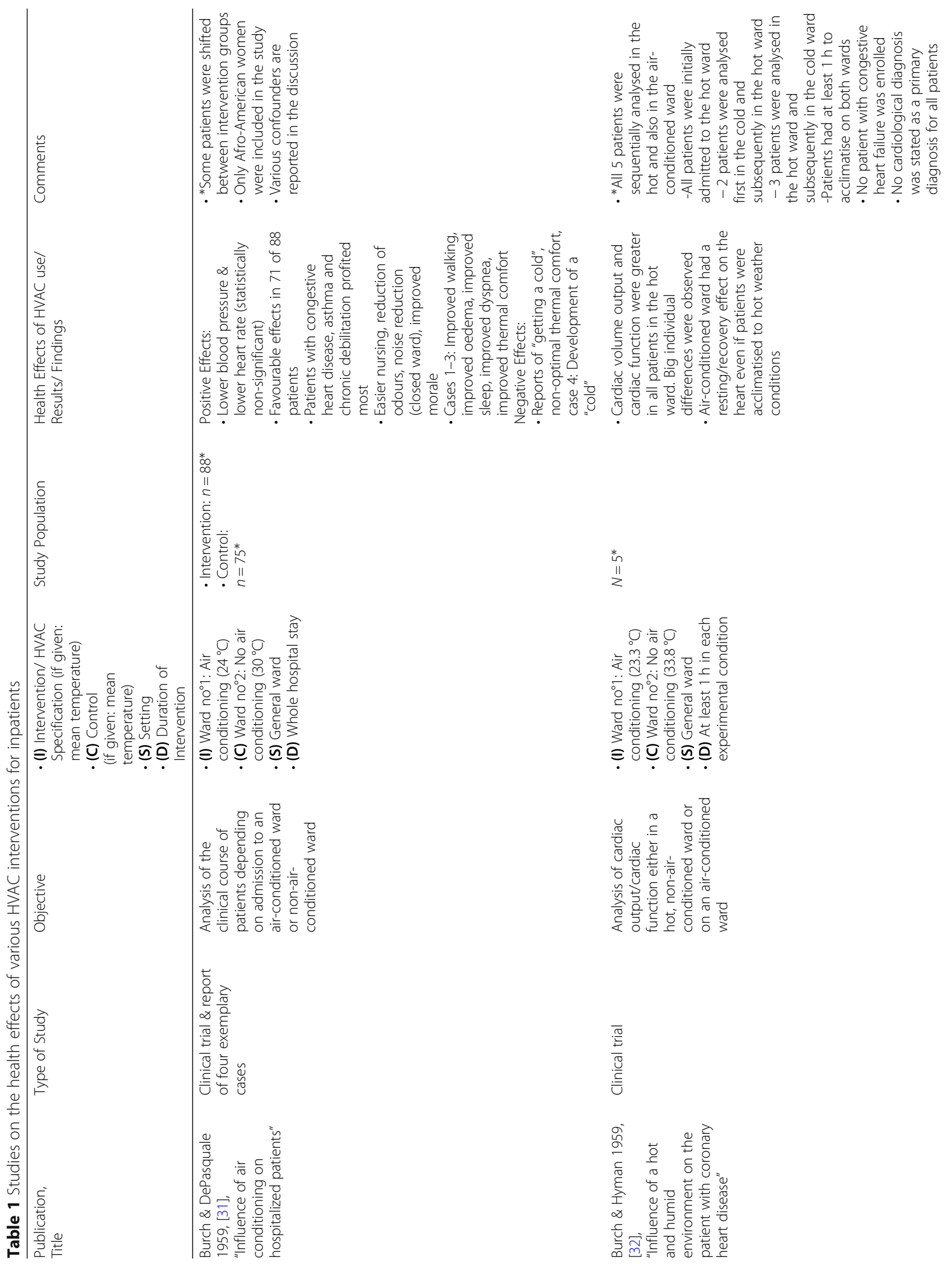




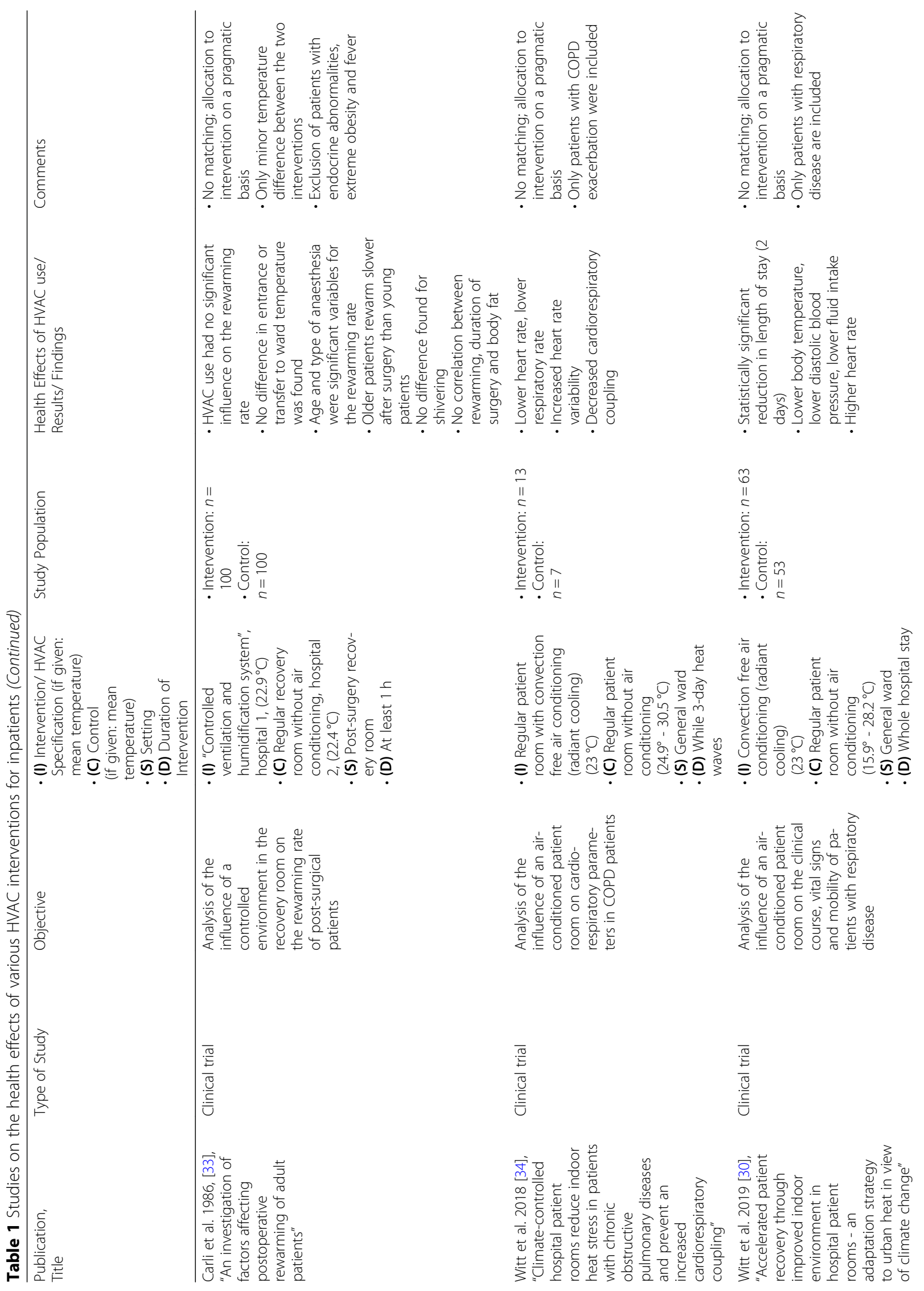




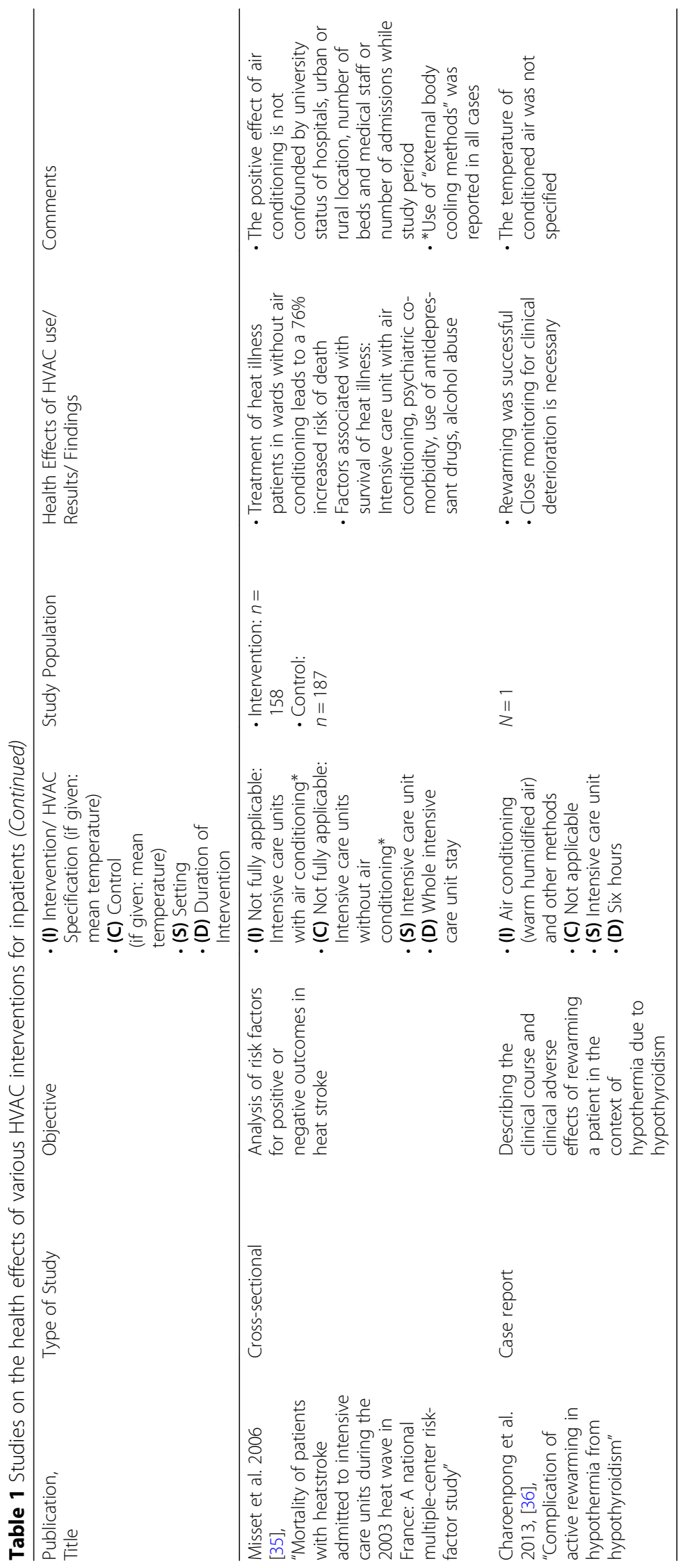




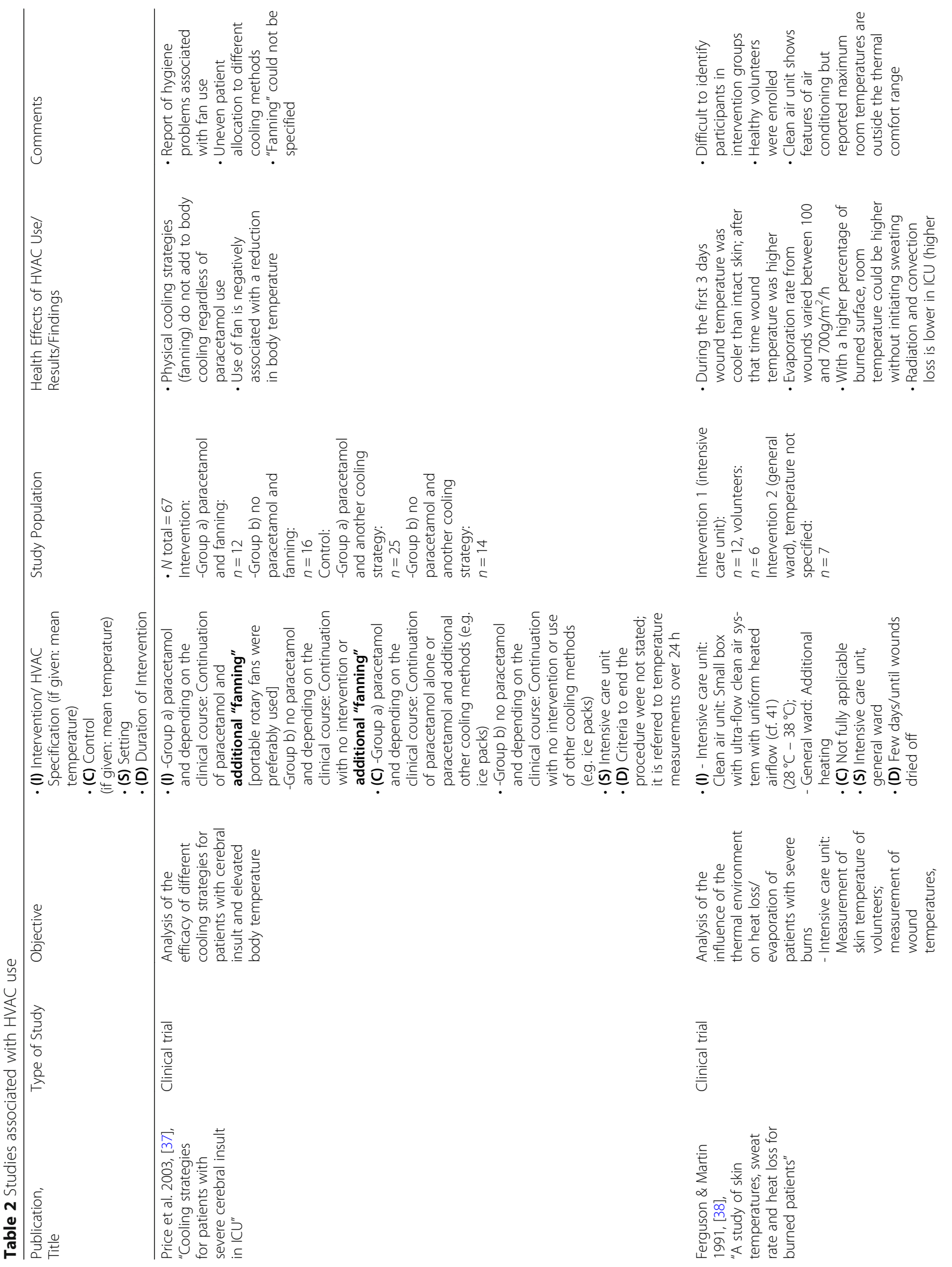




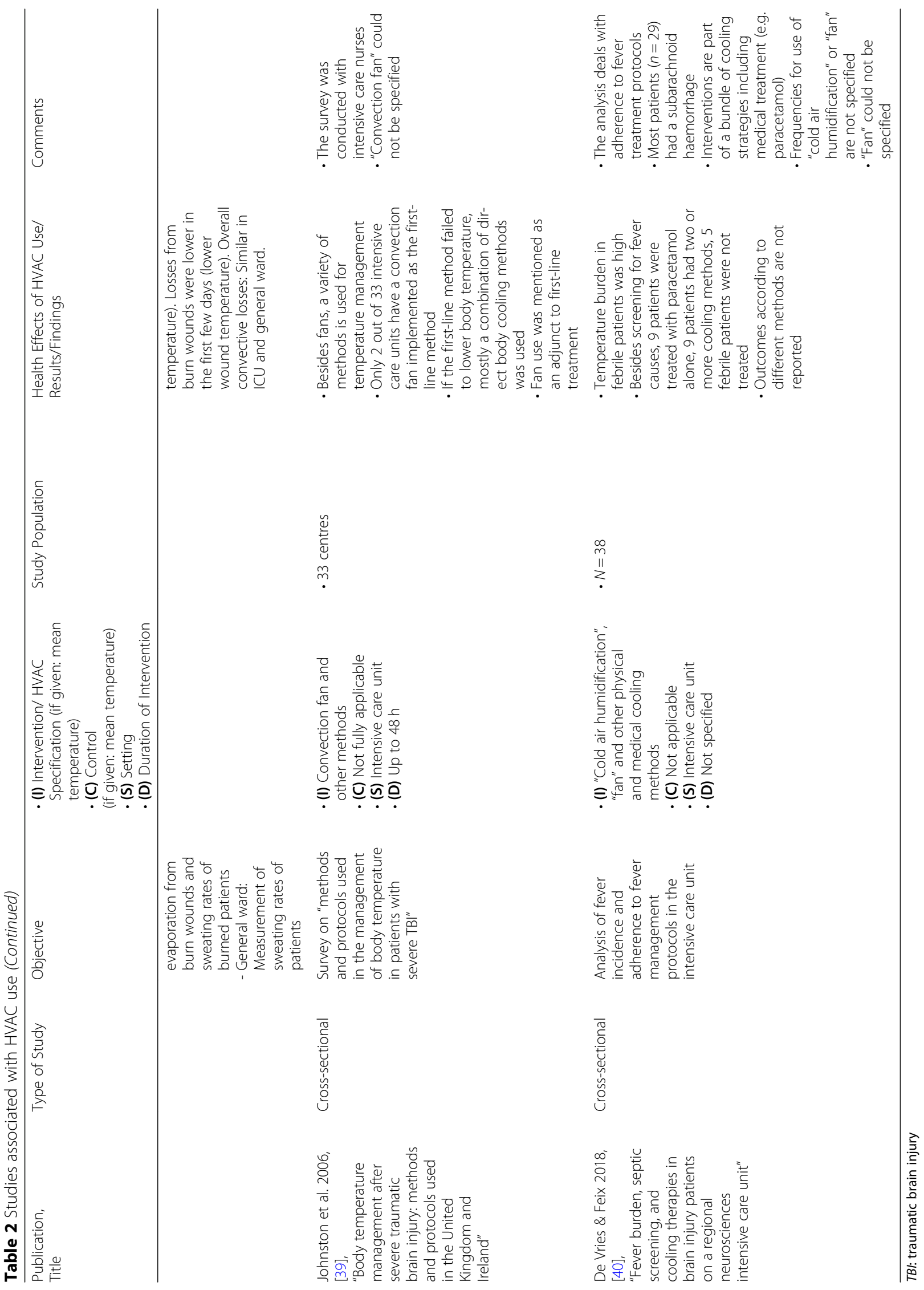


rewarming of hypothermic patients. HVAC was used in intensive care units and on general wards. Findings included patients from surgery and internal medicine. The technical specifications involved air conditioners, radiant cooling systems, special appliances (clean air unit) and fans. When applied while experiencing heat, HVAC use resulted in the improvement of physiologic parameters and greater mobility of inpatients. Health effects were mediated by alleviation of heat stress and an increase of the physiologic adaptive capacity of acutely ill patients. Negative aspects that were described included unfavourable thermal comfort or the feeling of getting sick. Notably, a shorter duration of hospital treatment and reduction of mortality were reported.

There are several limitations as some studies had small patient samples [32, 34, 36, 38], shifted patients between intervention and control group [31], included only one ethnic race and sex [31] or reported supplementary cooling methods [35]. The risk of bias and confounding is high owing to the absence or short description of randomisation or matching. Above all, HVAC use cannot be blinded. We are aware that the search strategy of this scoping review has a focus on inpatients of internal medicine. Therefore findings pertaining to other medical disciplines might not be represented. It is plausible that many findings are important for other specialities as well. HVAC use could e.g. be a particularly strong contributor to successful treatment in such areas as psychiatry, where treatment is especially influenced by environmental factors. However, the inclusion of further search terms was limited by the data handling capacity. Also, omitting pediatric patients leaves out a vulnerable group. However, the unique physiology and the diverging medical conditions justify a separate review. Differentiation between direct body cooling and air conditioning of the room was not possible for three of the 11 publications. In one study, an air conditioning system with an experimental design was used (cf. Table 2).

\section{Implications for research}

Despite abundant epidemiological findings confirming the adverse effects of heat on health, this scoping review shows that research on hospital adaptation and the individual treatment of inpatients is lacking. For future research projects, we propose to analyse the effects of HVAC

- on the physiology of inpatients experiencing heat or cold. The goal is to better understand the vulnerability of certain patient groups and to identify individuals that profit the most from a climatecontrolled indoor environment.
- to clarify the relationship between thermal comfort and health effects. Therefore patient satisfaction should be included as an outcome. The studies should cover groups not considered to be at highrisk for climate-related adverse health effects, too.

- to determine optimal technical settings for different patient groups and various hospital areas within the existing hospital infrastructure.

- on the health system. Costs, energy consumption, the efficiency of the medical treatment and ergonomics for health care workers should be investigated.

Future trials should randomise participants to the intervention and control group and report the extent of exposure to HVAC. Furthermore, medical treatment has to be standardised and HVAC specifications, as well as the outdoor climatic conditions, should be reported.

\section{Conclusion}

This scoping review provides valuable insight into the fields of application for HVAC and its health effects for inpatients. Due to the paucity of systematic research to date, no general recommendation for or against the use of HVAC for inpatients can be made. Publications on positive effects of heat stress protection for vulnerable groups are encouraging but more basic research regarding HVAC application is required for the development of evidence-based guidelines. The promising potential of HVAC to moderate climate change hazards has to be further explored.

\section{Supplementary information}

Supplementary information accompanies this paper at https://doi.org/10. 1186/s12889-020-09358-1.

Additional file 1. Full search strategy for databases.

Additional file 2. List of websites.

Additional file 3. Data charting form.

Abbreviations

HVAC: Heating, Ventilation and Air Conditioning; TBI: Traumatic Brain Injury

\section{Acknowledgements}

We would like to express our gratitude to the staff of the medical library of Charité - Universitätsmedizin Berlin for reviewing the search strategy.

Authors' contributions

$B L$ designed the study, acquired and analysed the data. He interpreted the results and drafted the manuscript. MR acquired and analysed the data. He critically revised the manuscript. $\mathrm{PH}$ interpreted the data and substantively revised the manuscript. $\mathrm{CH}$ designed the study, interpreted the data and substantively revised the manuscript. UL designed the study, analysed the data and interpreted the results. She critically revised the manuscript. All authors have read and approved the manuscript.

\section{Funding}

We acknowledge support from the German Research Foundation (DFG) and the Open Access Publication Fund of Charité - Universitätsmedizin Berlin to 
cover open access publishing fees. The funders did not exert any influence on the initiation and the design of the study, nor did the funders interfere with data collection and analysis, the interpretation of results or the writing of the manuscript. Open access funding provided by Projekt DEAL.

\section{Availability of data and materials}

The datasets used and/or analysed during the current study are available from the corresponding author on request.

\section{Ethics approval and consent to participate}

Not applicable.

\section{Consent for publication}

Not applicable.

\section{Competing interests}

The authors declare that they have no competing interests.

Received: 15 April 2020 Accepted: 5 August 2020

Published online: 26 August 2020

\section{References}

1. European Academies Science Advisory Council (EASAC): The imperative of climate action to protect human health in Europe. EASAC policy report 38. 2019.

2. Watts N, Amann M, Arnell N, Ayeb-Karlsson S, Belesova K, Berry H, et al. The 2018 report of the lancet countdown on health and climate change: shaping the health of nations for centuries to come. Lancet. 2018. https://doi.org/10.1016/S0140-6736(18)32594-7.

3. Petkova EP, Vink JK, Horton RM, Gasparrini A, Bader DA, Francis JD, et al. Towards more comprehensive projections of urban heat-related mortality: estimates for New York City under multiple population, adaptation, and climate scenarios. Env Health Perspect. 2017;125(1):47-55.

4. WHO Regional Office For Europe. Public Health and Climate Change Adaptation Policies in the European Union - Final Report. 2018. http://www. euro.who.int/_data/assets/pdf_file/0010/386965/Pagoda-REPORT-finalpublished-2.pdf?ua=1. Accessed 19 July 2019.

5. World Meteorological Organization (WMO). Climate statement: Past 4 years warmest on record. 2018. https://public.wmo.int/en/media/press-release/ climate-change-signals-and-impacts-continue-2018. Accessed 29 Nov 2018.

6. World Meteorological Organization (WMO). 2019 set to be 2nd or 3rd warmest year on record. 2019. https://public.wmo.int/en/media/news/2019set-be-2nd-or-3rd-warmest-year-record. Accessed 5 Feb 2020.

7. Guerreiro SB, Dawson RJ, Kilsby C, Lewis E, Ford A. Future heat-waves, droughts and floods in 571 European cities. Environ Res Lett. 2018;13(3): 034009 .

8. WHO Regional Office For Europe. Updating the evidence related to heat-health action planning - Meeting report. 2018. http://www.euro. who.int/__data/assets/pdf_file/0015/405330/HHAP-report.pdf?ua=1. Accessed 19 July 2019.

9. Witt C, Schubert AJ, Jehn M, Holzgreve A, Liebers U, Endlicher W, et al. The effects of climate change on patients with chronic lung disease. A systematic literature review. Dtsch Arztebl Int. 2015;112(51-52):878-83.

10. Kenny GP, Yardley J, Brown C, Sigal RJ, Jay O. Heat stress in older individuals and patients with common chronic diseases. CMAJ. 2010;182(10):1053-60.

11. Balmain BN, Sabapathy S, Louis M, Morris NR. Aging and thermoregulatory control: the clinical implications of exercising under heat stress in older individuals. Biomed Res Int. 2018;2018:8306154.

12. Hansen A, Bi P, Nitschke M, Ryan P, Pisaniello D, Tucker G. The effect of heat waves on mental health in a temperate Australian City. Environ Health Perspect. 2008;116(10):1369-75.

13. Shea KM. Global climate change and children's health. Pediatrics. 2007; 120(5):e1359-67.

14. Basu R, Samet JM. Relation between elevated ambient temperature and mortality: a review of the epidemiologic evidence. Epidemiol Rev. 2002; 24(2):190-202.

15. Aghdassi SJS, Schwab F, Hoffmann P, Gastmeier P. The Association of Climatic Factors with rates of surgical site infections: 17 years 'data from hospital infection surveillance. Dtsch Ärztebl Int. 2019;116(31-32):529.
16. Thompson R, Hornigold R, Page L, Waite T. Associations between high ambient temperatures and heat waves with mental health outcomes: a systematic review. Public Health. 2018;161:171-91.

17. Sundell J, Levin H, Nazaroff WW, Cain WS, Fisk WJ, Grimsrud DT, et al. Ventilation rates and health: multidisciplinary review of the scientific literature. Indoor Air. 2011;21(3):191-204.

18. McDermott BP, Casa DJ, Ganio MS, Lopez RM, Yeargin SW, Armstrong LE, et al. Acute whole-body cooling for exercise-induced hyperthermia: a systematic review. J Athl Train. 2009;44(1):84-93.

19. Leyk D. Health risks and interventions in exertional heat stress. Dtsch Arztebl Int. 2019;116(31-32):537-44.

20. Brown CF, Oldridge NB. Exercise-induced angina in the cold. Med Sci Sports Exerc. 1985;17(5):607-12.

21. Koskela H, Pihlajamäki J, Pekkarinen $\mathrm{H}$, Tukiainen $\mathrm{H}$. Effect of cold air on exercise capacity in COPD: increase or decrease? Chest. 1998;113(6):1560-5.

22. Secretariat MA. Air cleaning technologies: an evidence-based analysis. Ont Health Technol Assess Ser. 2005;5(17):1-52.

23. O'Neill MS, Zanobetti A, Schwartz J. Disparities by race in heat-related mortality in four US cities: the role of air conditioning prevalence. J Urban Health. 2005;82(2):191-7.

24. Theocharis G, Tansarli GS, Mavros MN, Spiropoulos T, Barbas SG, Falagas ME. Association between use of air-conditioning or fan and survival of elderly febrile patients: a prospective study. Eur J Clin Microbiol Infect Dis. 2013; 32(9):1143-7.

25. Nunes B, Paixao E, Dias CM, Nogueira P, Marinho FJ. Air conditioning and intrahospital mortality during the 2003 heatwave in Portugal: evidence of a protective effect. Occup Env Med. 2011;68(3):218-23.

26. Gupta R, Du H. Adapting the design of a new sustainable hospital building against a warming climate. Proceedings of BS; 2013. p. 2503-10.

27. Tricco AC, Lillie E, Zarin W, O'Brien KK, Colquhoun H, Levac D, et al. PRISMA extension for scoping reviews (PRISMA-SCR): checklist and explanation. Ann Intern Med. 2018;169(7):467-73.

28. Mourad Ouzzani HH, Fedorowicz Z, Elmagarmid A. Rayyan - a web and mobile app for systematic reviews. Syst Rev. 2016;5:210.

29. Shajahan A, Culp CH, Williamson B. Effects of indoor environmental parameters related to building heating, ventilation, and air conditioning systems on patients' medical outcomes: a review of scientific research on hospital buildings. Indoor Air. 2019;29(2):161-76.

30. Witt C, Drozdek M, Humbsch P, Kollek J, Hoffmann C, Bölke G, et al. Accelerated patient recovery through improved indoor environment in hospital patient rooms-an adaptation strategy to urban heat in view of climate change. Am J Respir Crit Care Med. 2019;199:A6011.

31. Burch GE, DePasquale N. Influence of air conditioning on hospitalized patients. JAMA. 1959:170(2):160-3.

32. Burch G, Hyman A. A study of the influence of tropical weather on output of volume, work, and power by the right and left ventricles of man at rest in bed. Am Heart J. 1959;57(2):247-54.

33. Carli F, Gabrielczyk M, Clark MM, Aber VR. An investigation of factors affecting postoperative rewarming of adult patients. Anaesthesia. 1986;41(4): 363-9.

34. Witt C, Kramer J, Liebers U, Drozdek M, Kurths J, Wessel N. Climatecontrolled hospital patient rooms reduce indoor heat stress in patients with chronic obstructive pulmonary diseases and prevent an increased cardiorespiratory coupling. Am J Respir Crit Care Med. 2018;197:A75.

35. Misset B, De Jonghe B, Bastuji-Garin S, Gattolliat O, Boughrara E, Annane D, et al. Mortality of patients with heatstroke admitted to intensive care units during the 2003 heat wave in France: a national multiple-center risk-factor study. Crit Care Med. 2006;34(4):1087-92.

36. Charoenpong P, Clarke C, Shahwan K, Poowanawittayakom N. Complication of active rewarming in hypothermia from hypothyroidism. Crit Care Med. 2013;141(12):A347.

37. Price T, McGloin S, Izzard J, Gilchrist M. Cooling strategies for patients with severe cerebral insult in ICU (part 2). Nurs Crit Care. 2003;8(1):37-45.

38. Ferguson JC, Martin CJ. A study of skin temperatures, sweat rate and heat loss for burned patients. Clin Phys Physiol Meas. 1991;12(4):367-75.

39. Johnston NJ, King AT, Protheroe R, Childs C. Body temperature management after severe traumatic brain injury: methods and protocols used in the United Kingdom and Ireland. Resuscitation. 2006;70(2):254-62.

40. De Vries TM, Feix B. Fever burden, septic screening, and cooling therapies in brain injury patients on a regional neurosciences intensive care unit. J Neurosurg Anesthesiol. 2018;30(1):95. 
41. Ferguson JC, Martin CJ. Burn wound evaporation--an evaluation of air diffusion resistances governing heat transfer in a clean air unit. Clin Phys Physiol Meas. 1989;10(4):319-30.

\section{Publisher's Note}

Springer Nature remains neutral with regard to jurisdictional claims in published maps and institutional affiliations.

Ready to submit your research? Choose BMC and benefit from:

- fast, convenient online submission

- thorough peer review by experienced researchers in your field

- rapid publication on acceptance

- support for research data, including large and complex data types

- gold Open Access which fosters wider collaboration and increased citations

- maximum visibility for your research: over $100 \mathrm{M}$ website views per year

At BMC, research is always in progress. 